\title{
Editorial
}

\section{EDITORIAL: New Academic Year and New Beginnings}

\author{
Betül C. Czerkawski \\ Editor, ITLT
}

\begin{abstract}
This volume introduces three especially enlightening and astute works that aid in our navigation and understanding of learning technologies. First is Rebecca Smith's article, which determines that technology is compelling in its ability to increase teacher confidence. The second is by Donna Hess, which exemplifies that instructional design principles backed by a theoretical approach are critical in conceiving compelling foreign language practices. The third, by Megan Motto, establishes that routine practice and contemplation with a coaching peer facilitates more efficient technology use within the classroom. These three papers come to the conclusion that technology within the classroom does not assure achievement unless that technology is used alongside a theoretical and pedagogical foundation. Furthermore, our journal will be undergoing important changes, as I am stepping down as editor and Dr. Gerald Ardito will assume my position in January of 2022.
\end{abstract}

Keywords: Deeper Learning Framework, foreign language teaching, TPACK model, Issues and Trends in Learning Technologies

We start the new academic year with renewed hopes for the future. We have three exceptionally informative and insightful works to help us see where we are heading with learning technologies. The first article of the issue is a research article by Rebecca Smith, who investigated lecture-capture technologies using Darling-Hammond et al.'s Deeper Learning Framework (2018) within preservice teacher education context. This study shows that technology could be very effective in increasing the confidence of teacher candidates; however, appropriate modeling and mentoring should accompany the teacher training. Dr. Smith's study demonstrates once again that learning technologies is an applied field, and that active and contextual learning strategies result in positive outcomes for the teacher candidates. The second article, by Donna Hess, presents a literature review of instructional design (ID) models that could be used in foreign language teaching. Donna's paper demonstrates that instructional design principles supported by a theoretical approach are essential in creating effective foreign language practices. Considering that many adult learners are learning foreign languages in online settings, instructional design becomes particularly important for online student success, so Don- 
na's paper is must-read for those who are planning to teach online. The third article, by Megan Motto, focuses on teacher professional development as noted in the technological, pedagogical, and content knowledge (TPACK) model, and investigates the impact of coaching practices for career and technical schools. Megan's study with six high school teachers demonstrates that continuous practice and reflection with a coaching peer enables more effective technology use in the classroom. All three papers indicate that using technology in the classroom does not guarantee success unless that technology is used in conjunction with a theoretical and pedagogical basis.

Speaking of the new academic year, I would like to announce an important change in our Journal. I started Issues and Trends in Learning Technologies in 2013 as an open access journal. I was very lucky to work with some of the most talented former and current students from the University of Arizona, including Max Liberman, Eugene Lyman, Margherita Berti, and Rachel Ramona Arvizu. However, it was Dr. Nicole Schmidt, our managing editor, and her distinguished work that have made the journal possible. Nicole has a very bright future, as everyone who worked with her knows. I wish all ITLT editors great success. It is time for a change in the journal, so I am stepping down as the editor of ITLT, while passing the torch to a dear friend and colleague, Dr. Gerald Ardito. Starting from January 2022, Gerald will be the new ITLT editor. I have known Gerald for 5 years, and he has proven to be an exceptional scholar who has dedicated his life to the educational computing field. Currently, he is an associate professor of computer science education and program head at the Manhatanville College. His work is truly exceptional, so I am confident that future ITLT contributors will enjoy working with him.

Onward and upward! 